\title{
Optimization of Adhesive Layer Thickness at Metal Bonding Using Quick-Setting Adhesives
}

\section{Milan Brožek}

Department of Material Science and Manufacturing Technology, Faculty of Engineering, Czech University of Life Sciences Prague. Kamýcká 129, 16521 Praha 6 - Suchdol, Czech Republic. brozek@tf.czu.cz

In the contribution the results of bonded joints laboratory tests are published. For bonding of test samples five different types of quick-setting adhesives were used. The determination of the tensile lap-shear strength of rigidto-rigid bonded assemblies according to the standard CSN EN 1465 (66 8510) was the aim of carried out tests. The samples were made from steel and duralumin sheets. Ahead of bonding the surfaces of all samples were blasted using corundum grit and degreased. Bonded joints of different adhesive layer thickness were tested. The layer thickness was secured using two copper wires of the appropriate diameter, which were placed between the bonded surfaces. By the test results evaluation the optimum adhesive layer thicknesses were determined, when the concrete bonded joint strength is the highest.

Keywords: adhesive bonding, quick-setting adhesives, technological properties of adhesives, testing of bonded joints

\section{References}

[1] BOLIBRUCHOVÁ, D., BRU゚NA, M. (2013): Effect of Germanium on Secondary Lead-free Tin Solders. Manufacturing Technology. XIII, 2013, 3: 281-289.

[2] BROCKMANN, W. et al. (2009): Adhesive bonding: materials, applications and technology. Weinheim, Wiley-VCH.

[3] BROŽEK, M. (2003a): Studium faktorů ovlivňujících pevnost lepených spojů (Study of factors influencing the bonded joint strength). Strojárstvo/Strojírenství, Žilina, Media ST, 7, 7/8: 54 - 55.

[4] BROŽEK, M. (2003b): Vliv tloušt'ky vrstvy lepidla na pevnost lepeného spoje (Influence of adhesive layer thickness on bonded joint strength). MM Průmyslové spektrum, Praha, Industria Press, 1/2: 72.

[5] BROŽEK, M. (2003c): Vliv doby vytvrzování lepidla na pevnost lepených spojů (Influence of adhesive curing time on bonded joint strength). MM Prưmyslové spektrum, Praha, Industria Press, 7/8: 67.

[6] BROŽEK, M. (2013a): Technical-economical evaluation of plywood bonding. In.: $5^{\text {th }}$ International Conference Trends in Agricultural Engineering. 3. - 6. 9. 2013. Czech University of Life Sciences Prague: 100-105.

[7] BROŽEK, M. (2013b): Soldering sheets using soft solders. Acta Univ. Agric. Silvic. Mendel. Brun., 61(6), 1597-1604; doi:10.11118/actaun201361061597.

[8] BROŽEK, M. - MÜLLER, M. (2004): Mechanické vlastnosti spojů lepených sekundovými lepidly. Strojírenská technologie, IX, 1:9 - 15.

[9] CAGLE, Ch.V. (1973): Handbook of adhesive bonding. New York, Mac-Graw-Hill.

[10] COGNARD, P. (2006): Adhesives and sealants: general knowledge, application techniques, new curing techniques. Oxford, Elsevier.

[11] EBNESAJJAD, S. (2008): Adhesives technology handbook. $2^{\text {nd }}$ ed. Norwich, William Andrew.

[12] EPSTEIN, G. (1954): Adhesive bonding of metals. New York, Reinhold.

[13] GARRON, P. (1977): Analysis and testing of adhesive bonds. New York, Academie Press.

[14] KAŠPAR, Z. - BROŽEK, M. (2005): Vliv drsnosti povrchu hliníku na pevnost lepených spojů. Strojírenská technologie. X, 2005, 3: 5 - 10 .

[15] KOVAČIČ, Ĺ. (1984): Lepenie kovov a plastov (Adhesive bonding of metals and plastics). $2^{\text {nd }}$ ed. Bratislava, Alfa.

[16] KŘÍŽ, R. (1994): Strojírenská př́ručka (Engineering handbook). Vol. 5. Praha, Scientia.

[17] LOCTITE (1988): Der Loctite. München, Loctite.

[18] MÜLLER, M. - BROŽEK, M. (2005): Technologie lepení - vliv expirační doby na pevnost lepených spojů. Strojírenská technologie. X, 2005, 3: 10 - 16.

[19] MÜLLER, M. - BROŽEK, M. - VALÍČEK, J. (2009): Interakce vlivu integrity lepeného povrchu a tloušt'ky vrstvy lepidla na proces lepení. Strojírenská technologie, XIV, 2009, 3: 18 - 25. 
[20] NOVÁKOVÁ, A., BROŽEK, M. (2009): Bonding of non-metallic materials using thermoplastic adhesives. In.: $8^{\text {th }}$ International Scientific Conference Engineering for Rural Development. 28. - 29. 5. 2009. Latvia University of Agriculture, Jelgava: 261 - 264.

[21] OSTEN, M. (1996): Práce s lepidly a tmely (Work with adhesives and cements). Praha, Grada Pubishing.

[22] PETERKA, J. (1980): Lepení konstrukčních materiáli̊ ve strojírenství (Bonding of construction materials in engineering). Praha, SNTL 1980.

[23] PIZZI, A., MITTAL, K.L. (2003): Handbook of adhesive technology. Dekker, New York.

[24] SADEK, M. (1987): Industrial application of adhesive bonding. London, Elsevier Applied Sciency.

[25] ČSN EN 1465 (66 8510). (2009): Lepidla - Stanovení pevnosti ve smyku při tahovém namáhání přeplátovaných lepených sestav (Adhesives - Determination of tensile lap-shear strength of bonded assemblies). Praha, ČNI. 